\title{
Conceptualized Simulation for Templating Carbon Based Nano Structures for Li-ion Batteries: A DFT Investigation
}

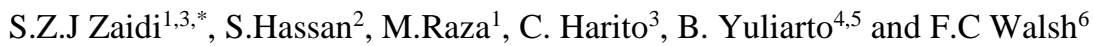 \\ ${ }^{1}$ Institute of Chemical Engineering and Technology, University of the Punjab, Lahore, Pakistan \\ ${ }^{2}$ Mechanical Engineering, Faculty of Engineering and Physical sciences, University of Southampton, U.K \\ ${ }^{3}$ Industrial Engineering Department, Faculty of Engineering, Bina Nusantara University, 11480 Jakarta, Indonesia. \\ ${ }^{4}$ Advanced Functional Materials (AFM) Laboratory, Engineering Physics, Institut Teknologi Bandung, 40132, Bandung, \\ Indonesia \\ ${ }^{5}$ Research Center for Nanosciences and Nanotechnology (RCNN), Institut Teknologi Bandung, 40132, Bandung, Indonesia \\ ${ }^{6}$ Electrochemical Engineering Lab, Energy Technologies, University of Southampton, U.K
}

Corresponding Author Email: Zohaib.icet@pu.edu.pk

\begin{abstract}
CNT $(10,0)$ is carbon nanotube; Graphene is a 2-dimensional carbon allotrope being light weight and Chitosan is a linear polysaccharide. In this work, detailed analysis of the above three stated compounds as anode for lithium-ion batteries is stated. The density function theory (DFT) computations were used to carry out the investigation of the above stated compound as anode materials for the lithium-ion batteries. The analysis shows that Graphene and Chitosan are highly favorable to be used as anodes materials for the lithium-ion batteries. The results show that the Vcell of Graphene and Chitosan when they are used as an anode for lithium-ion batteries are extremely higher as compared to CNT $(10,0)$ at 5.632 Volts, 4.719 Volts and 1.22 Volts, respectively.
\end{abstract}

Keywords: lithium-ion batteries, carbon nanotubes, graphene, chitosan Received: February-03-2021, Accepted: April-15-2021, https://doi.org/10.14447/jnmes.v24i2.a02

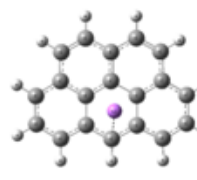

Graphene

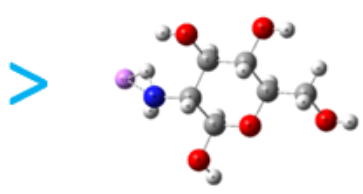

Chitosan

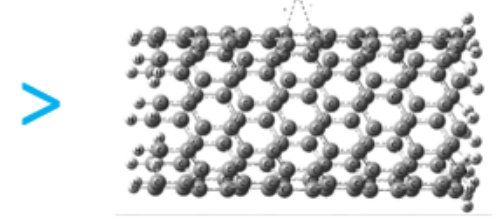

CNT

\section{DFT Improvements in Carbon based nano-electrodes for Li ion batteries}

\section{INTRODUCTION}

The Lithium-ion battery is a highly dense and rechargeable electric battery that can be recharged multiple times during its lifetime and the Lithium-ion battery works by lithium ions transfer from the positive electrode called anode and towards the negative electrode called cathode through charging and discharging process again and again [1-3]. Before, numerous research papers have been published on the topic of effectiveness of different anode materials for the Lithium-ion batteries [4-6].

Graphene has wild array of applications ranging from Pharmaceuticals and energy storage to materials and semiconductor industries [7, 8]. The nanomaterials synthesized from different sources, mainly carbon have been used to report improved performance in batteries [9-11].

It is extremely important for development and large scale commercial adoption of Lithium-Ion batteries that they have extremely high energy density because are competing against fossil fuels and they hold extremely high energy density [1217]. Improved performance was reported by using nanomaterials and Graphene as anode in the performance and storage of batteries [18-23].

Furthermore, studies have been done showing that the addition of Graphene in batteries results high capacity over long runs and also high capacity retention [24]. The Graphene is an amazing material and many studies have proved its ability to improve batteries [25-28].

In this study, CNT $(10,0)$, Graphene and Chitosan were selected as possible anode materials for the lithium-ion batteries and studied through theoretical models in Gaussian and Avogadro software.

\section{DFT COMPUTATIONAL SIMULATION PACKAGE SELECTION AND APPLICATION}

First of all, Avogadro was used for Optimization of the structures and then the structures of Graphene, Chitosan and CNT $(10,0)$ were with Lithium formed a metal complex and was geometrically optimized to a minimum by DFT/B3LYP method and basis set was $6-31++G$ (d). Vibrational Frequencies were calculated at the same level that the optimized geometries are at true local minima. 
The reaction that are taking place in the positive and negative electrodes of the Lithium-ion batteries with the theoretical nanostructure of anode can be described as (The Liion/Nanostructure $\leftrightarrow \mathrm{Li}$-ion ++ electron-)for the positive electrode and (Li-ion ++ electron- $\leftrightarrow$ Li-ion) for the negative electrode of the Li-ion battery. Also, the overall reaction at both positive and negative electrodes of the Lithium-ion battery can be written as ( $\mathrm{Li}$-ion++ $\mathrm{L}$-ion/nanostructure $\leftrightarrow \mathrm{Li}$ ion + /nanostructure $+\mathrm{Li}$-ion $+\Delta$ Gcell1). For calculations of the voltage produced by the battery (Vcell) we use the Nernst equation .Vcell $=-\Delta \mathrm{Gcell} / \mathrm{zF}$, in this formula $\mathrm{F}$ is defined as the Faraday constant and its value is taken as $(96,500$ $\mathrm{C} / \mathrm{mol}$ )where $\mathrm{z}$ is the charge of Li-ion+ in the Li-ion battery.

\section{RESULTS AND DISCUSSIONS}

The Values of $E_{a d}$ of Lithium-ion on surface of Graphene, Chitosan and Carbon Nano Tubes $(10,0)$ are given in table 1.The adsorption energies of Li-ion nanostructures that were under observation negative, so Li-ion was stabilized on surface of nanostructures that were under observation from the point of view of energy.

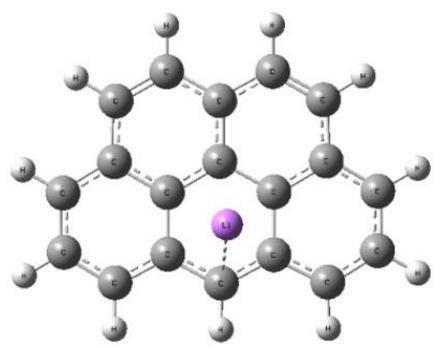

(a)

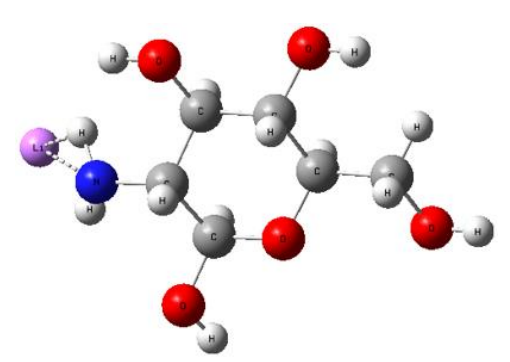

(b)

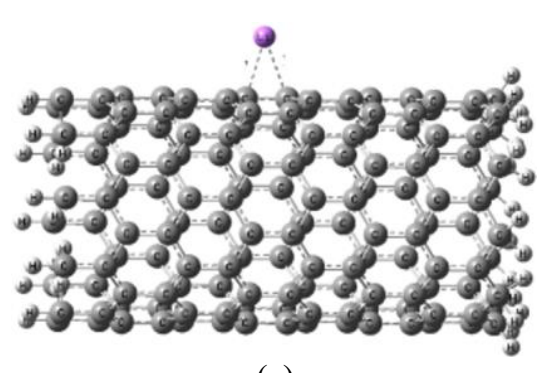

(c)

Figure 1. DFT structure of Li-ion complexes a) Graphene-Li b) Chitosan-Li c) CNT $(10,0)$

3.1

3.1.1 $\mathrm{V}_{\text {cell }}$ comparison

Table 1. Adsorption energies are expressed in $\left(\mathrm{E}_{a d}\right.$ in kilo calories per mole ), Highest occupied molecular orbital's energy (EHOMO in electron Volts), energy of Lowest unopccupied molecular orbitals (ELUMO in electron

Volts)Gap energy of HOMO-LUMO Orbital ( $\mathrm{E}_{g}$ in electron Volts) and cell voltage (Vcell in Volts) of Li-ion on the surface of observed carbon nano tubes $\operatorname{CNT}(10,0)$ (The values were obtained by DFT and B3LYP functional in Gaussian software).

\begin{tabular}{cccccc}
\hline Structure & $E_{\text {ad }}$ & $E_{\text {homo }}$ & $E_{\text {lumo }}$ & $E_{g}$ & $V_{\text {cell }}$ \\
\hline Graphene-li & -0.4015 & -4.0115 & -1.2825 & 2.729 & 5.632 \\
Chitosan-li & -16.309 & -2.9456 & -0.8974 & 2.0482 & 4.719 \\
CNT (10,0)-li & -21.00 & -8.49 & -3.37 & 5.12 & 1.22 \\
\hline
\end{tabular}

Table 2. Comparable nanostructures [31]

\begin{tabular}{|c|c|c|c|c|c|}
\hline C-Li-ion Nanostructures & $E_{a d}$ & $E_{\text {homo }}$ & $E_{\text {lumo }}$ & $E_{g}$ & $V_{\text {cell }}$ \\
\hline $\mathrm{C}_{60}-\mathrm{Li}$ & -15.82 & -6.99 & -2.86 & 4.13 & 0.71 \\
\hline $\mathrm{C}_{72}-\mathrm{Li}$ & -17.08 & -7.22 & -3.04 & 4.18 & 0.81 \\
\hline $\mathrm{C}_{60}-\mathrm{NH}_{2}-\mathrm{Li}$ & -21.70 & -7.37 & -3.15 & 4.22 & 1.00 \\
\hline $\mathrm{C}_{72}-\mathrm{NH}_{2}-\mathrm{Li}$ & -23.80 & -7.55 & -3.26 & 4.29 & 1.06 \\
\hline $\mathrm{C}_{60}-\mathrm{Li}^{+}$ & -31.50 & -10.45 & -5.69 & 4.76 & ------ \\
\hline $\mathrm{C}_{72}-\mathrm{Li}^{+}$ & -35.00 & -10.82 & -6.01 & 4.81 & ------ \\
\hline $\mathrm{C}_{60}-\mathrm{NH}_{2}-\mathrm{Li}^{+}$ & -43.82 & -11.19 & -6.31 & 4.88 & ------ \\
\hline $\mathrm{C}_{72}-\mathrm{NH}_{2}-\mathrm{Li}^{+}$ & -47.18 & -11.57 & -6.62 & 4.95 & ----- \\
\hline $\operatorname{CNT}(8,0)-\mathrm{Li}$ & -18.34 & -8.11 & -3.34 & 4.77 & 1.10 \\
\hline CNT $(10,0)-\mathrm{Li}$ & -21.00 & -8.49 & -3.37 & 5.12 & 1.22 \\
\hline $\mathrm{CNT}(8,0)-\mathrm{NH}_{2}-\mathrm{Li}$ & -24.64 & -8.95 & -3.47 & 5.48 & 1.25 \\
\hline CNT $(10,0)-N_{2}-\mathrm{Li}$ & -26.04 & -9.23 & -3.57 & 5.66 & 1.32 \\
\hline CNT $(8,0)-\mathrm{Li}^{+}$ & -42.56 & -12.3 & -6.12 & 6.19 & ----- \\
\hline CNT $(10,0)-\mathbf{L i}^{+}$ & -47.88 & -12.78 & -6.56 & 6.22 & $---\cdot$ \\
\hline CNT $(8,0)-N_{2}-\mathrm{Li}^{+}$ & -52.36 & -13.06 & -6.75 & 6.31 & - \\
\hline CNT $(10,0)-\mathrm{NH}_{2}-\mathrm{Li}^{+}$ & -55.30 & -13.62 & -7.14 & 6.48 & \\
\hline
\end{tabular}

The Table 1 shows all the calculated values of $V_{\text {cell }}$ of the studied structure. Graphene and Chitosan have a very high $V_{\text {cell }}$ as compared to CNT $(10,0)$. The highest $V_{\text {cell }}$ is that of Graphene. The $V_{\text {cell }}$ of Graphene, Chitosan and CNT $(10,0)$ are 5.632 Volts, 4.719 Volts and 1.22 Volts respectively. Graphene and Chitosan outperform CNT by a huge margin. When we compare different nanaostructure from Table 1 and Table 2, we can see easily that graphene and Chitosan have almost double the $V_{\text {cell }}$ as compared to CNTs.

\subsection{2 $E_{a d}$ comparison}

The calculated values of $E_{a d}$ are reported in Table 1 . The $E_{a d}$ of Graphene is least negative as compared to that of CNT (10, $0)$ and Chitosan. The absolute value of $E_{a d}$ of CNT $(10,0)$ is higher than Chitosan and Graphene at $-21 \mathrm{kcal} / \mathrm{mol},-16.309$ $\mathrm{kcal} / \mathrm{mol}$ and $-0.4015 \mathrm{kcal} / \mathrm{mol}$ respectively. The order of $E_{a d}$ in terms of Absolute values is as follows: CNT $(10,0)>$ Chitosan $>$ Graphene.

\subsection{3 $E_{g}$ comparison}

From the calculated values of Egas shown in Table 1, the homo-lumo band gap $\left(E_{g}\right)$ is the highest in CNT $(10,0)$ and then after it Graphene has the highest gap and at last is Chitosan.

The $E_{g}$ values of Graphene, Chitosan and CNT $(10,0)$ complexes with Lithium-ion are $2.729 \mathrm{eV}, 2.0482 \mathrm{eV}$ and 5.12 eV respectively. In Table 1 and Table2, different nanostructure is shown to have higher $E_{g}$ it means that Graphene and Chitosan have better ability to lose and gain electron due to a lower homo-lumo gap which also results in a higher voltage potential of the cell.

\subsection{Comparison of graphene and chitosan intermediate geometries}

From Figure 2(a) it can be clearly seen that Graphene Lithium complex is extremely stable as compared to the Chitosan as can be seen from Figure 2(b) which has more turbulent movement of lithium in the Chitosan-Lithium complex. 


$$
\begin{gathered}
\text { G. } \\
\text { G-1 }
\end{gathered}
$$

Figure 2. Intermediate optimized geometry states of Graphene, 9 different transition states of graphene before achieving the most optimized structure starting from top left 1 to bottom right 9. Pink is lithium, silver are carbon and white atoms are hydrogen

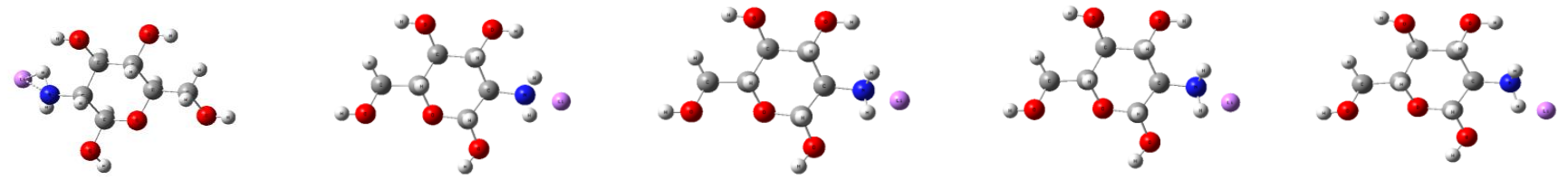

$$
\begin{aligned}
& \text { G-1 G-2 } \\
& \log _{0}^{0} \\
& \text { G-2 G-3 } \\
& \log _{0}^{0} \\
& \log _{0}^{0} \\
& \text { G-4 } \\
& \text { G-5 } \\
& \text {.0 } \\
& \text { G-8 } \\
& \text { G-9 } \\
& \text { \% } \\
& \text { G-7 }
\end{aligned}
$$
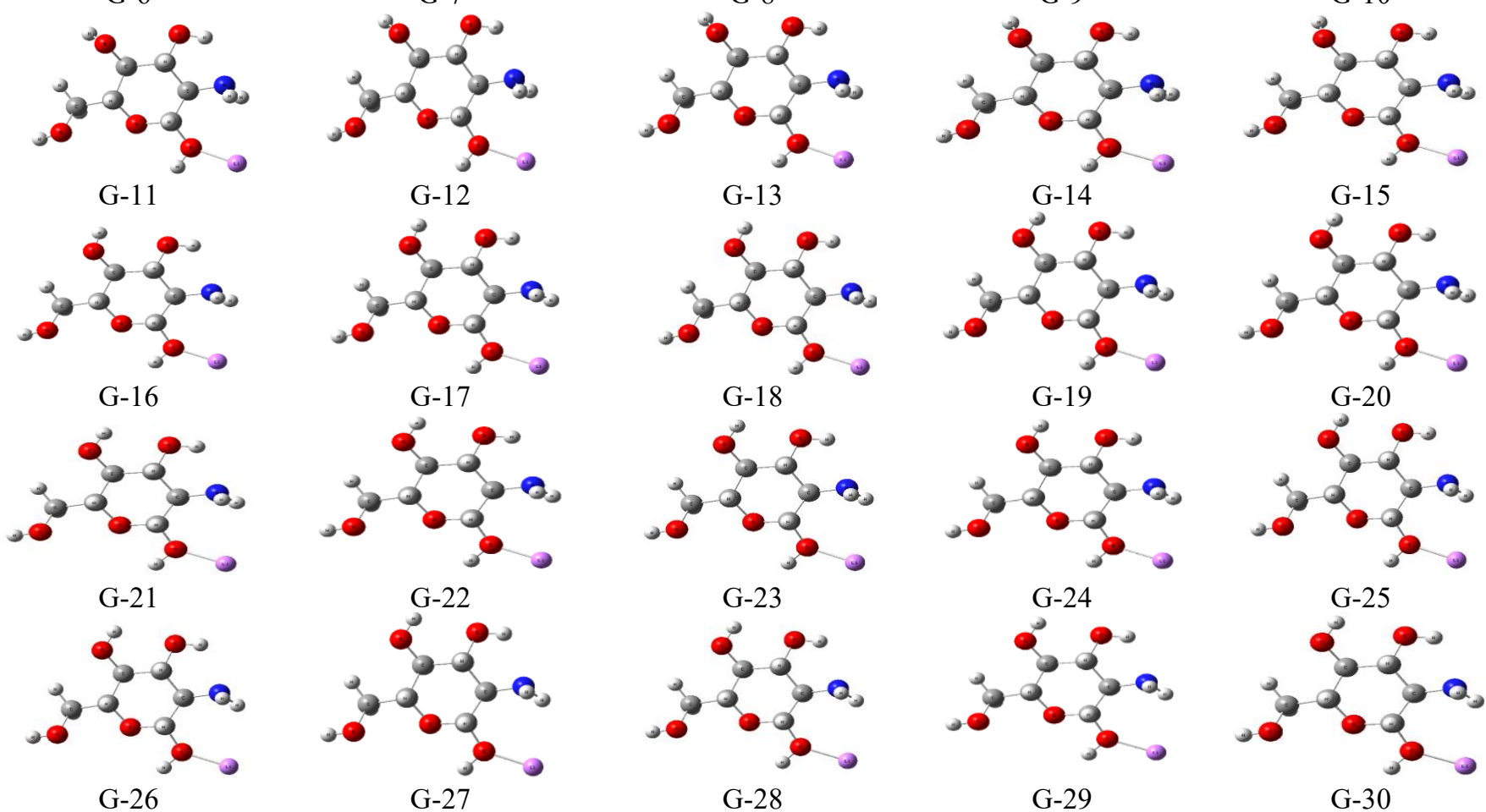


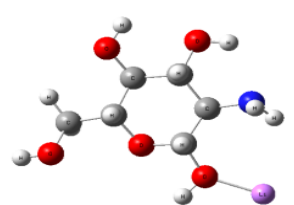

G-31

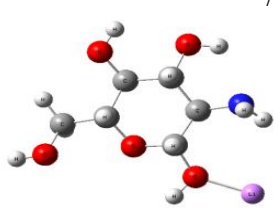

G-32 J. New Mat. Electrochem. Systems

Figure 3. Intermediate optimized geometry states of Chitosan, 35 different transition states of Chitosan starting from top left at 1 to bottom right at 35 . Pink atom is Lithium, blue is nitrogen, white is hydrogen, red is oxygen

From Figure 4, this shows Graphene total energy in hartree against the step number. The optimization of Graphene is achieved in 9 steps. The energy decrease is also stable.

In Figure 5, there is a sudden spike in energy in step number 10 , but it after step 10 starts to decrease again and optimization is achieved in 35 steps.

From the Optimization steps and the intermediate geometries shown in Figure 4 and Figure 2(a), it can be clearly seen that the Graphene complex of Lithium at anode is extremely stable. It means that Graphene is a very favorable compound to be used as anode in Lithium-ion batteries.

In comparison to graphene and lithium complex, the Chitosan and Lithium complex as shown From Figure 2(b) has a lot of Geometrical intermediaries. It has 35 Geometrical Intermediaries.

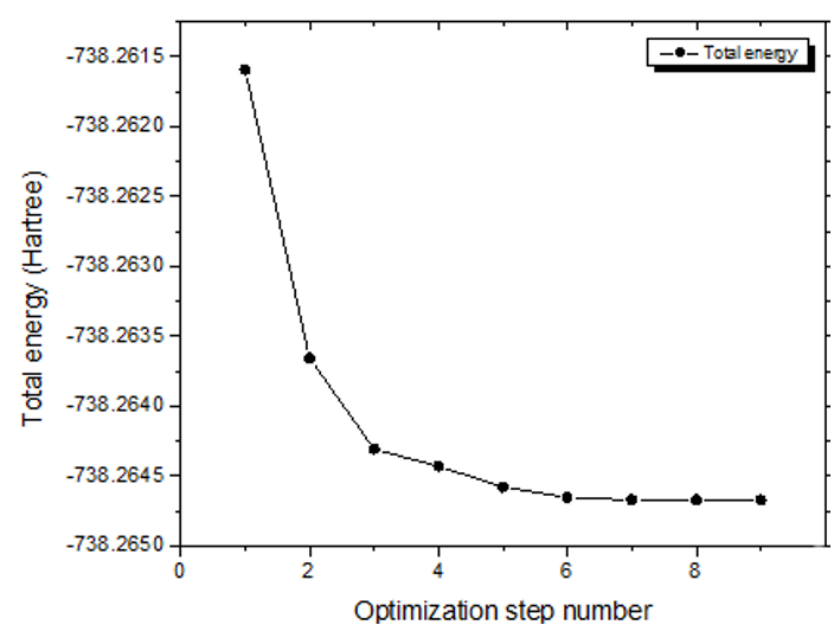

Figures 4. Optimization vs. total energy plot for the identification of total energy for Graphene

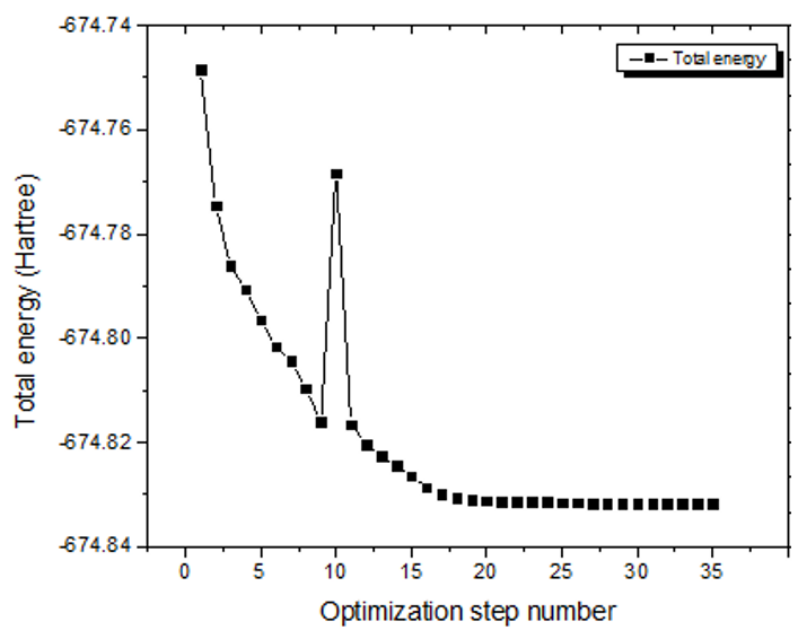

Figure 5. Optimization vs. total energy plot for the identification of total energy for Chitosan

\subsubsection{Battery modeling of graphene}

A 2-D battery modeling of graphene was carried out using Comsol- Multiphysics software. As graphene also has a 2-D structure, which will help give accurate results.

The battery structure is shown in Figure 6(a) and 6(b), a rectangular battery with extremely thin anode is shown in 6(a) and 6(b), the thin anode represents graphene. LiPF6 was used as electrolyte with EC and DMC used in ratio 1:2.

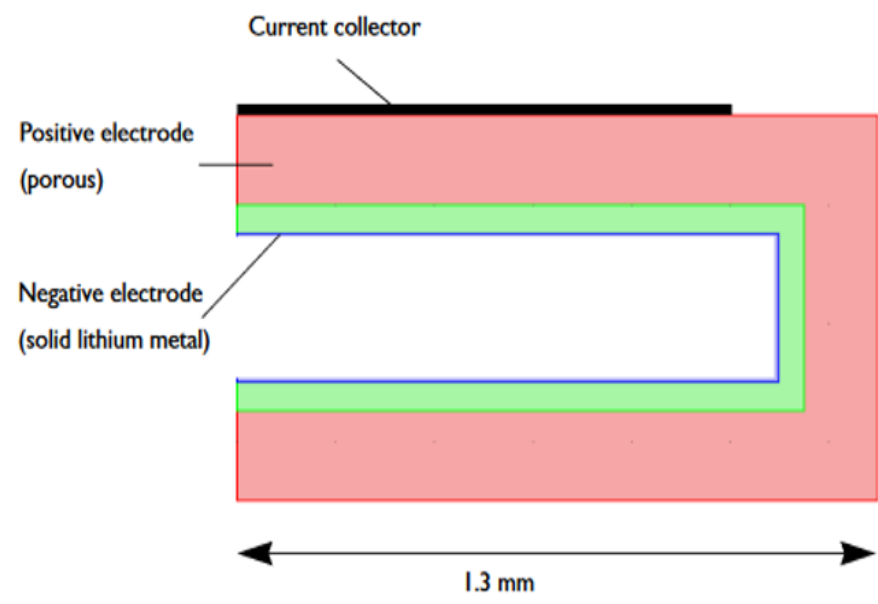

Figure 6(a). The li-ion battery 2-D model

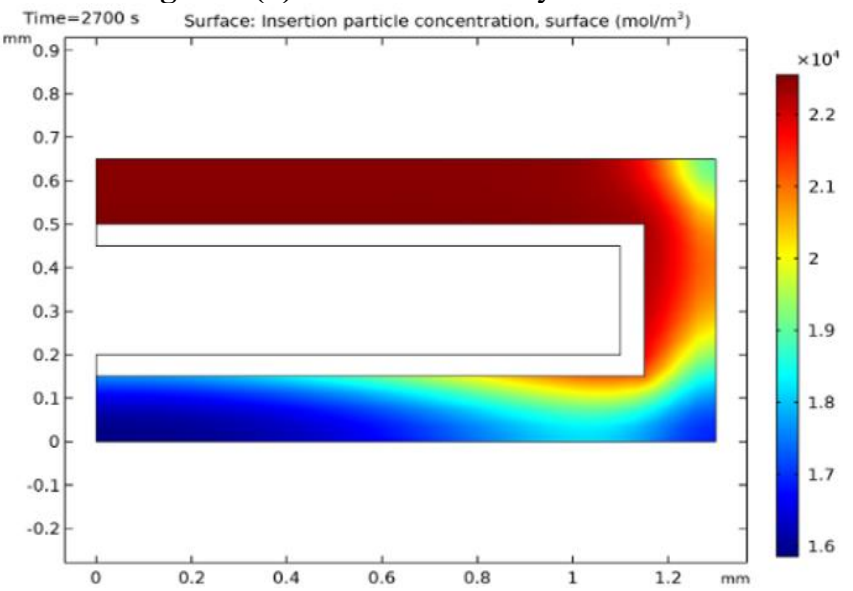

Figure 6(b). Lithium concentration in the battery

\subsubsection{Results of battery modeling}

Figure 7(a) shows the $\mathrm{li}^{+}$ion concentration at anode at electrode length of $1 \mathrm{~mm}$ and $0.55 \mathrm{~mm}$. The closer we are at anode, higher the concentration of $\mathrm{li}^{+}$ion. It shows the higher attractiveness of graphene for lithium-ion.

The electrode potential and SOC are shown in Figure 7(b) and (c) respectively. The electrode potential remains very potential throughout the whole discharge cycle. The average SOC increase as the time increases. 


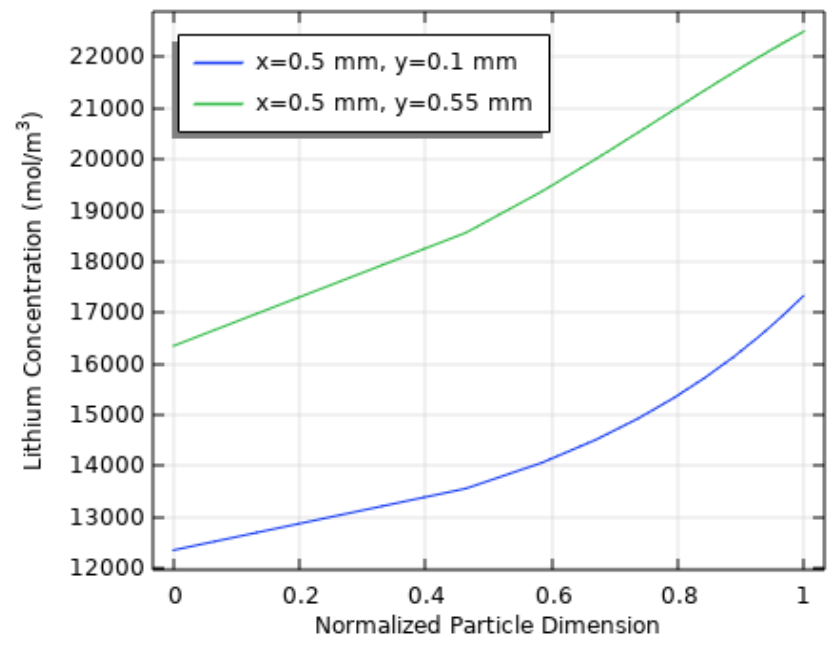

Figure 7(a). Lithium concentration at positive electrode at $\mathrm{t}=2700 \mathrm{~s}$

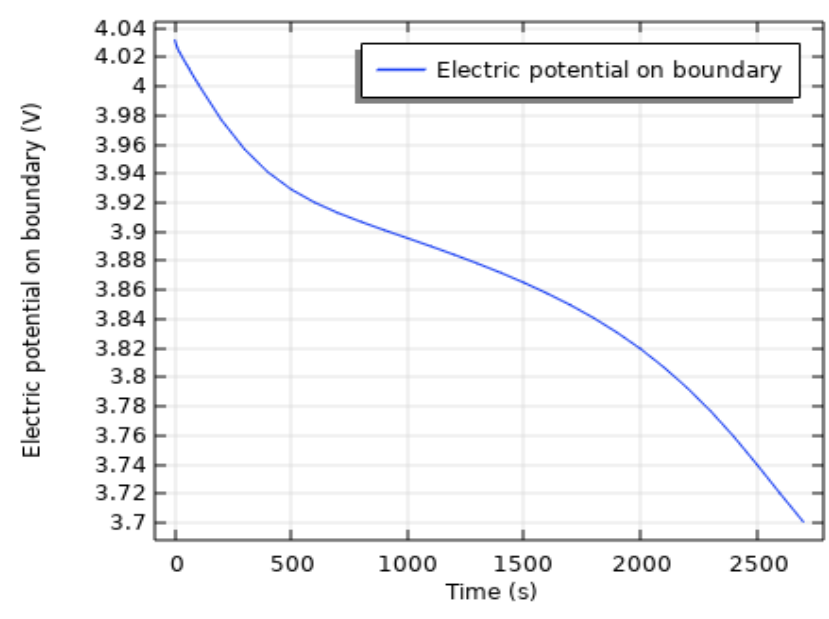

Figure 7(b). Electric potential on boundary

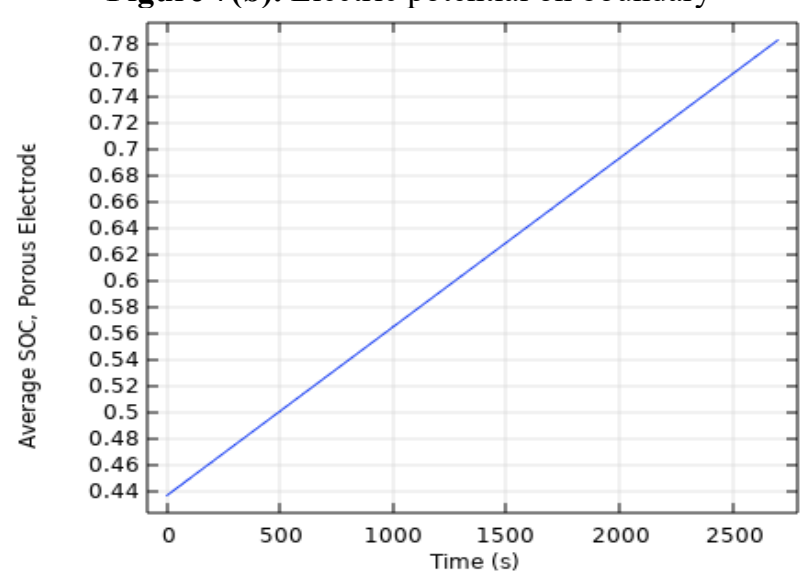

Figure 7(c). Average state of charge

\subsection{CV and Capacity vs cycle no}

In the figure $8(a)$, we can see Cyclic voltammetry of Graphene at 6 continuous scan rates, from $0.005 \mathrm{mV} / \mathrm{s}$ to 0.10 $\mathrm{V} / \mathrm{s}$. The simulation duration for this was from $2700 \mathrm{~s}$ to $1 \mathrm{~s}$. The currents are increasing with scan rate, but the cyclic voltammety of Graphene have the exact qualitative "doublepeaked" visual aspect. The double peak can be explained by the fact that the voltage range at the beginning is not enough to drive the forward reaction of the reactant at anode, so we observe negligible current. As the voltage range increase, the rate of reaction is also accelerated, so we observe increase in current. After passage of some time we observe that the reactant concentration is depleted as a result of the reaction at the positive electrode surface. Then There is a change of ratedetermining process, so that the current essentially is controlled by diffusion of the reactant which brings it up to the surface, and thereby we observe it fall off again. We observe the similar process, but in reverse, for the charge cycle in which the product is again converted to the original reactant as the voltage is brought back to the starting point.

Figure 8(b) and (c) show the specific capacity vs cycle no and capacitance ratio, the capacitance ratio remains extremely constant throughout the many charge/ discharge cycles [30, 31].

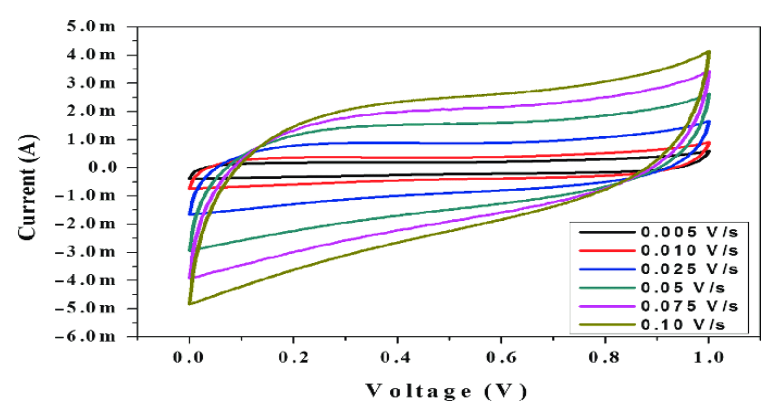

Figure 8 (a). Cyclic voltammetry of Graphene [32]

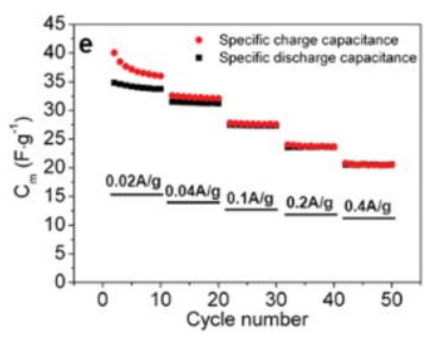

Figure 8(b). Specific capacitance dependance on the current

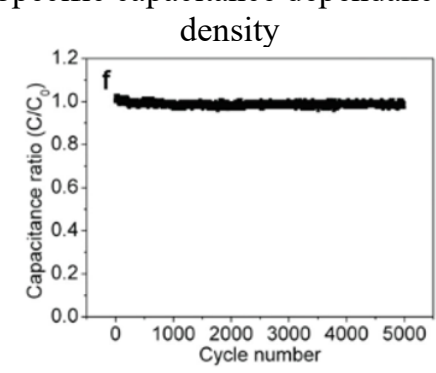

Figure 8 (c). Specific capacitance vs cycle number of the graphene /CNT composite fiber electrode

\subsection{SEM, TEM and AFM images of Graphene nanolayer}

Figure 9(a)-(c) shows TEM, AFM and SEM images of graphene. Figure $9(\mathrm{c})$ is showing the image of graphene at 10 micrometer. We can see the site at which the $\mathrm{li}^{+}$ion will be deposited at anode in the lithium-ion battery. Figure 9(a) shows large holes in the graphene layer. During charging cycle, the $\mathrm{li}^{+}$ion can easily de-intercalate from the anode, this will lead to a stable structure and fast charging of the $\mathrm{li}^{+}$ion batteries [32, 33]. 


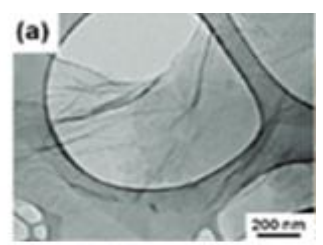

Figure 9(a). Graphene TEM images

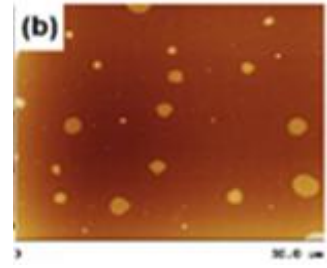

Figure 9(b). AFM image of Graphene

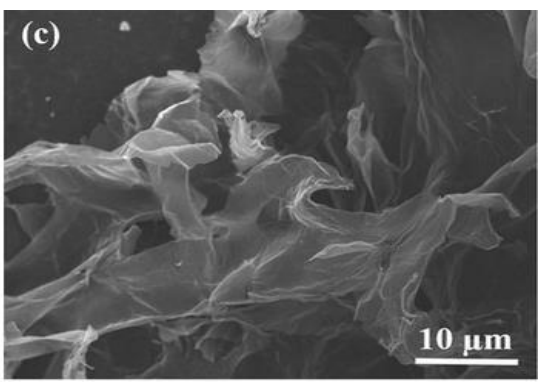

Figure 9(c). SEM image of graphene nanosheets

\section{CONCLUSION}

In this Paper the Density function theory method was used to calculate how complexes of Graphene and Chitosan as anode materials for lithium batteries would affect the performance of a lithium-ion battery. CNT $(10,0)$ was used as reference. The results were extraordinary, Graphene Vcell value was 5.632 Volts while that of Chitosan was 4.719 Volts, it was huge compared with CNT $(10,0)$ value of 1.22 Volts.

Currently, Research is being carried out to make batteries out of diverse range of carbon based nano materials to help improve batteries performance [34-35].

It is imperative that more research be carried out using these two as anode materials for lithium-ion batteries. We need to keep working on better materials to improve the performance of batteries and help the transition towards green, sustainable energy technologies development.

\section{REFERENCES}

[1] Zheng, J.W., Nai, S.M.L., Ng, M.F., Wu, P., Wei, J., Gupta, M. (2009). DFT study on nano structures of $\mathrm{Sn} / \mathrm{CNT}$ complex for potential Li-ion battery application. The Journal of Physical Chemistry C, 113(31): 1401514019. https://doi.org/10.1021/jp809266n

[2] Flandrois, S., Simon, B. (1999). Carbon materials for lithium-ion rechargeable batteries. Carbon, 37(2): 165180. https://doi.org/10.1016/S0008-6223(98)00290-5

[3] Yazami, R. (2000). Materials for Li-Ion Batteries, Julien, C., Stoyhov, Z., Eds.

[4] Yanbio, R., Shichao, Z., Lincai, Z., Xiowu, H. (2019). Journal of Materials Research and Technology.
[5] Wan, H., Hu, X. (2019). Nitrogen doped biomassderived porous carbon as anode materials of lithium ion batteries. Solid State Ionics, 341: 115030. https://doi.org/10.1016/j.ssi.2019.115030

[6] Wang, F., Yuan, H., Huang, J. (2020). A bio-inspired nanofibrous $\mathrm{Co} 3 \mathrm{O} 4 / \mathrm{TiO} 2 /$ carbon composite as highperformance anodic material for lithium-ion batteries. Journal of Alloys and Compounds, 819: 153375. https://doi.org/10.1016/j.jallcom.2019.153375

[7] Li, L., Jiang, G., Ma, J. (2018). CuMn2O4/graphene nanosheets as excellent anode for lithium-ion battery. Materials Research Bulletin, 104: 53-59. https://doi.org/10.1016/j.materresbull.2018.03.051

[8] Singh, V., Joung, D., Zhai, L., Das, S., Khondaker, S.I., Seal, S. (2011). Graphene based materials: past, present and future. Progress in materials science, 56(8): 11781271. https://doi.org/10.1016/j.pmatsci.2011.03.003

[9] Knoop, J.E., Ahn, S. (2020). Recent advances in nanomaterials for high-performance $\mathrm{Li}-\mathrm{S}$ batteries. Journal of Energy Chemistry, 47: 86-106. https://doi.org/10.1016/j.jechem.2019.11.018

[10] Demir, E., Soytas, S.H., Demir-Cakan, R. (2019). Bismuth oxide nanoparticles embedded carbon nanofibers as self-standing anode material for $\mathrm{Na}$-ion batteries. Solid State Ionics, 342: 115066. https://doi.org/10.1016/j.ssi.2019.115066

[11] Uddin, M.J., Alaboina, P.K., Cho, S.J. (2017). Nanostructured cathode materials synthesis for lithiumion batteries. Materials Today Energy, 5: 138-157. https://doi.org/10.1016/j.mtener.2017.06.008

[12] Cao, W., Zhang, J., Li, H. (2020). Batteries with high theoretical energy densities. Energy Storage Materials, 26: 46-55. https://doi.org/10.1016/j.ensm.2019.12.024

[13] Leonard, M.D., Michaelides, E.E., Michaelides, D.N. (2020). Energy storage needs for the substitution of fossil fuel power plants with renewables. Renewable Energy, 145: 951-962. https://doi.org/10.1016/j.renene.2019.06.066

[14] Fathy, A., Rezk, H., \& Nassef, A. M. (2019). Robust hydrogen-consumption-minimization strategy based salp swarm algorithm for energy management of fuel cell/supercapacitor/batteries in highly fluctuated load condition. Renewable energy, 139: 147-160. https://doi.org/10.1016/j.renene.2019.02.076

[15] Raj, H., Singh, S., Sil, A. (2019). TiO2 shielded Si nanocomposite anode for high energy Li-ion batteries: The morphological and structural study of electrodes after charge-discharge process. Electrochimica Acta: 326, 134981. https://doi.org/10.1016/j.electacta.2019.134981

[16] Li, Y., Yang, J., Song, J. (2016). Structural model, size effect and nano-energy system design for more sustainable energy of solid state automotive battery. Renewable and Sustainable Energy Reviews, 65: 685697. https://doi.org/10.1016/j.rser.2016.07.063

[17] Kim, T.S., Lim, J.E., Oh, M.S., Kim, J.K. (2017). Carbon conductor-and binder-free organic electrode for flexible organic rechargeable batteries with high energy density. Journal of Power Sources, 361: 15-20. https://doi.org/10.1016/j.jpowsour.2017.06.059

[18] Y, S, Park, S., Kang, Y. (2019). Chemical Engineering Journal, 370: 1008-1018.

[19] Bensalah, N., Kamand, F.Z., Mustafa, N., Matalqeh, M. (2019). Silicon-Germanium bilayer sputtered onto a carbon nanotube sheet as anode material for lithium-ion 
batteries. Journal of Alloys and Compounds, 811: 152088. https://doi.org/10.1016/j.jallcom.2019.152088

[20] Park, G.D., Kang, Y.C. (2019). Aerosol-assisted synthesis of porous and hollow carbon-carbon nanotube composite microspheres as sulfur host materials for highperformance Li-S batteries. Applied Surface Science, 495:

143637. https://doi.org/10.1016/j.apsusc.2019.143637

[21] Yan, Z., Yang, Q.W., Wang, Q., Ma, J. (2020). Nitrogen doped porous carbon as excellent dual anodes for Li-and Na-ion batteries. Chinese Chemical Letters, 31(2): 583588. https://doi.org/10.1016/j.cclet.2019.11.002

[22] De las Casas, C., Li, W. (2012). A review of application of carbon nanotubes for lithium ion battery anode material. Journal of Power Sources, 208: 74-85. https://doi.org/10.1016/j.jpowsour.2012.02.013

[23] Greenspon, A. (2017). The Energy Storage Landscape: Feasibility of Alternatives to Lithium Based Batteries. Harvard Energy Journal Club.

[24] Zhao, X., Li, H., Han, F., Dai, M., Sun, Y., Song, Z., Niu, L. (2020). Electrochemical exfoliation of graphene as an anode material for ultra-long cycle lithium ion batteries. Journal of Physics and Chemistry of Solids, 139: 109301. https://doi.org/10.1016/j.jpcs.2019.109301

[25] Han, P., Zhao, Y. (2020). Facilely self-assembled $\mathrm{MnS} / \mathrm{S}$-doped reduced graphene oxide network with enhanced performance for potassium-ion battery. Materials Letters, 264: 127367. https://doi.org/10.1016/j.matlet.2020.127367

[26] Huang, H., Rao, P., Choi, W.M. (2019). Carbon-coated silicon/crumpled graphene composite as anode material for lithium-ion batteries. Current Applied Physics, 19(12): 1349-1354. https://doi.org/10.1016/j.cap.2019.08.024

[27] Kang, J.H., Chen, J.S. (2018). Using ethylenediamine to prepare three dimensional nitrogen-doped graphene aerogel/sulfur composite for lithium-sulfur batteries. Diamond and Related Materials, 88: 222-229. https://doi.org/10.1016/j.diamond.2018.07.015

[28] Mo, R., Lei, Z., Rooney, D., Sun, K. (2019). Anchored monodispersed silicon and sulfur nanoparticles on graphene for high-performance lithiated silicon-sulfur battery. Energy Storage Materials, 23: 284-291. https://doi.org/10.1016/j.ensm.2019.04.046

[29] Najafi, M. (2017). Application of C60, C72 and carbon nanotubes as anode for lithium-ion batteries: A DFT study. Materials Chemistry and Physics, 195: 195-198. https://doi.org/10.1016/j.matchemphys.2017.04.032

[30] Ramli, N.I., Ismail, N.A.B., Abd-Wahab, F., Salim, W.W.A.W. (2018). Cyclic Voltammetry and electrical impedance spectroscopy of electrodes modified with PEDOT: PSS-reduced graphene oxide composite. In Transparent Conducting Films. IntechOpen.

[31] Sun, H., You, X., Deng, J., Chen, X., Yang, Z., Ren, J., Peng, H. (2014). Novel graphene/carbon nanotube composite fibers for efficient wire-shaped miniature energy devices. Advanced Materials, 26(18): 2868-2873. https://doi.org/10.1002/adma.201305188

[32] Yu, A., Park, H.W., Davies, A., Higgins, D.C., Chen, Z., Xiao, X. (2011). Free-standing layer-by-layer hybrid thin film of graphene-MnO2 nanotube as anode for lithium ion batteries. The Journal of Physical Chemistry Letters, 2(15): 1855-1860. https://doi.org/10.1021/jz200836h

[33] Yasin, G., Arif, M., Shakeel, M., Dun, Y., Zuo, Y., Khan, W. Q., Nadeem, M. (2018). Exploring the NickelGraphene Nanocomposite Coatings for Superior Corrosion Resistance: Manipulating the Effect of Deposition Current Density on its Morphology, Mechanical Properties, and Erosion-Corrosion Performance. Advanced Engineering Materials, 20(7): 1701166. https://doi.org/10.1002/adem.201701166

[34] Ogasawara, T., Débart, A., Holzapfel, M., Novák, P., Bruce, P.G. (2006). Rechargeable Li2O2 electrode for lithium batteries. Journal of the American Chemical Society, 128(4): 1390-1393. https://doi.org/10.1021/ja056811q

[35] Lin, Z., Liu, Z., Dudney, N.J., Liang, C. (2013). Lithium superionic sulfide cathode for all-solid lithium-sulfur batteries. ACS Nano, 7(3): 2829-2833. https://doi.org/10.1021/nn400391h

$\begin{array}{ll}\text { ABBREVIATIONS } \\ \text { DFT } & \text { Density function theory } \\ \text { B3LYP } & \text { Becke-3 Parameter Lee, Yang and Parr } \\ \text { CNT } & \text { Carbon nanotube } \\ \text { HOMO } & \text { Highest occupied molecular orbital } \\ \text { LUMO } & \text { Lowest unoccupied molecular orbit } \\ \text { E }_{\mathrm{g}} & \text { The energy between HOMO-LUMO } \\ & \text { orbitals } \\ \mathrm{E}_{\mathrm{ad}} & \text { Adsorption energy of the elections in Li-ion } \\ & \text { battery } \\ \text { Vcell } & \text { Cell Voltage }\end{array}$

\section{ABBREVIATIONS}

